\title{
DE SCHRIJFDOOS BIDSPRINKHAAN VAN UEMATSU HŌBI
}

Uematsu Hōbi (I872-I933) was een lakmeester van de oude stempel. Anders dan zijn vooruitstrevende tijdgenoten, die graag hun individuele kunstenaarschap benadrukten, signeerde hij zijn werk vaak niet. Bovendien werkte hij in een archaïserende stijl, die voornamelijk teruggreep op de Muromachi-periode (I392-I568). Binnen zijn oeuvre is de schrijfdoos Bidsprinkhaan enigszins een buitenbeentje.

\section{Ontwerp}

Met opgericht lijf staat de bidsprinkhaan triomfantelijk bovenop een smakelijk glanzende aubergine (afb. I). Zijn driehoekige kopje heeft hij omgedraaid, waardoor hij ons recht in de ogen kijkt. De voelsprieten steken omhoog in de lucht. Hij maakt een alerte indruk.

De vorm van deze schrijfdoos is tamelijk ongewoon door de 'ingetrokken' hoeken en 'ingetrokken' rand van het deksel (afb. 2). De hoeken en de rand worden nog meer geaccentueerd doordat zij besprenkeld zijn met goudsnippers. Een dergelijke vorm heb ik slechts eenmaal eerder gezien, en dat was bij een schrijfdoos van Hōbi's vader Uematsu Hōmin (I845I902), van wie hij het vak leerde.

De binnenkant is van een eenvoudige chic; de gouden kleur contrasteert met de zwarte buitenkant (afb. 3). Het hele oppervlak van de binnenkant van het deksel en van het losse houten blad dat de inktsteen en de waterdruppelaar draagt, maar ook van de binnenkant van de bodem onder het houten blad, is bedekt met verspreide planten met uitwaaierende blaadjes die van bovenaf gezien zijn afgebeeld.

De zwarte waterdruppelaar is gemaakt van shakudō en laat een versiering zien van een ring kalebassen omgeven door bladeren.

De betekenis van het ontwerp is volkomen onduidelijk. Aangezien de afbeelding van een bidsprinkhaan op een aubergine een terugkerend thema in de Japanse kunst vormt, ligt een specifieke betekenis voor de hand. Traditioneel staat de bidsprinkhaan symbool voor moed, maar dat lijkt hier niet bijzonder relevant te zijn. Volgens de handelaar in Tokyo, van wie ik de schrijfdoos kocht, zou de bidsprinkhaan in combinatie met een aubergine verwijzen naar een Japans gezegde, al kon hij daar het fijne niet van vertellen. Recente navraag in Japan leverde evenmin een exacte verklaring op, behalve dat de combinatie wellicht louter gezien moet worden als een aanduiding voor de late zomer. In elk geval vormt de aubergine niet het voedsel voor de bidsprinkhaan, want deze insecten zijn pure vleeseters. Wel zal hij zich tegoed doen aan de luizen en kleine insecten, die zich op de schil van de vrucht bevinden. 


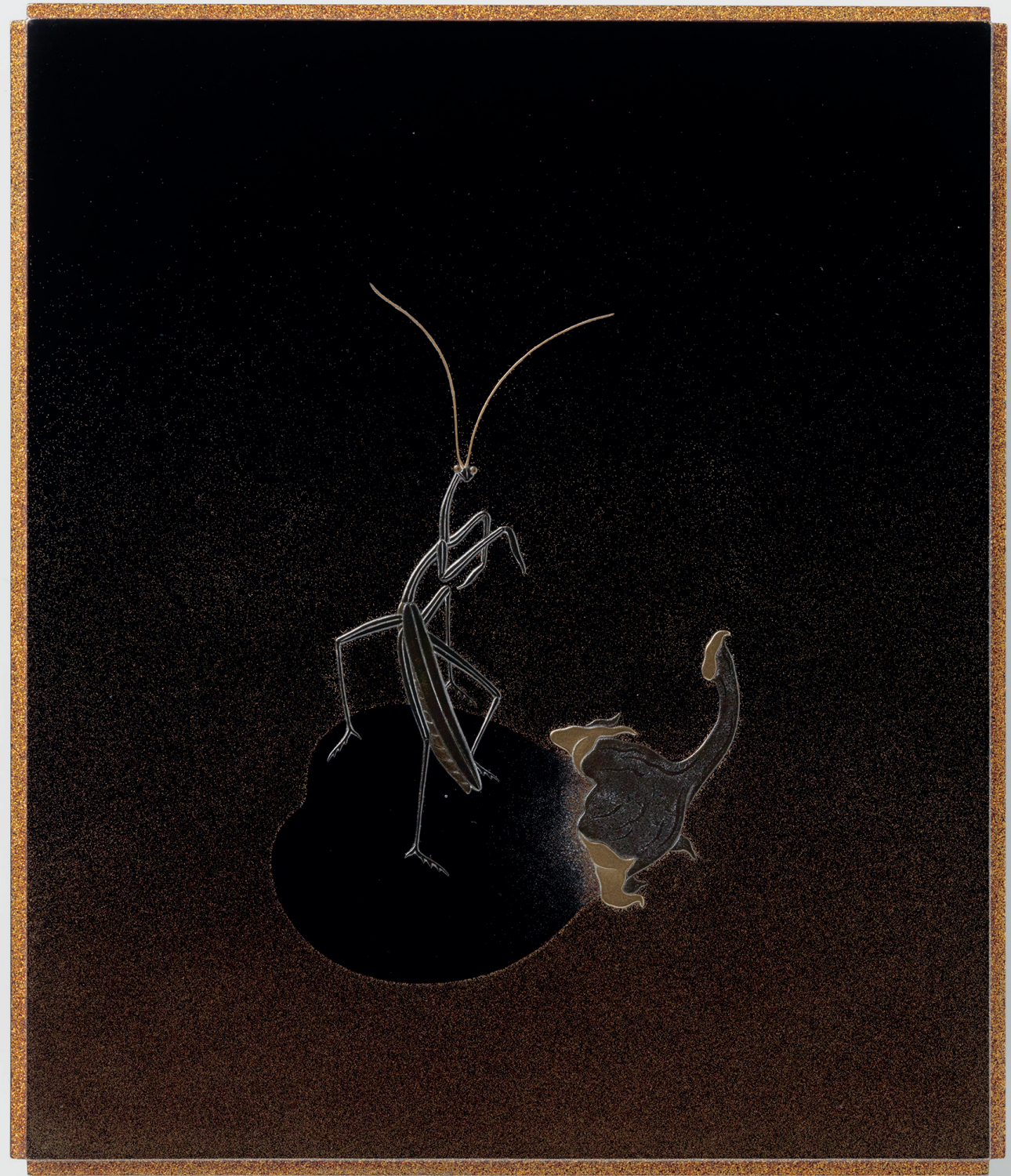

Afb. 1

Buitenaanzicht van de schrijfdoos Bidsprinkhaan,

Uematsu Hōbi, 21,4 x 18,1 x 4,3 cm., Japan, ca. 1910,

Rijksmuseum, Amsterdam, inv.nr. AK-C-2012-14-12,

bruikleen Jan Dees \& René van der Star
Afb. 2 (rechtsboven)

In het schuine aanzicht

is duidelijk te zien dat

de randen en de hoeken

van de schrijfdoos zijn

'ingetrokken'
Afb. 3 (rechtsonder)

Binnenkant van

de schrijfdoos

met inktsteen,

waterdruppelaar en

twee penselen

Downloaded from Brill.com๑4/26/2023 01:42:48PM 

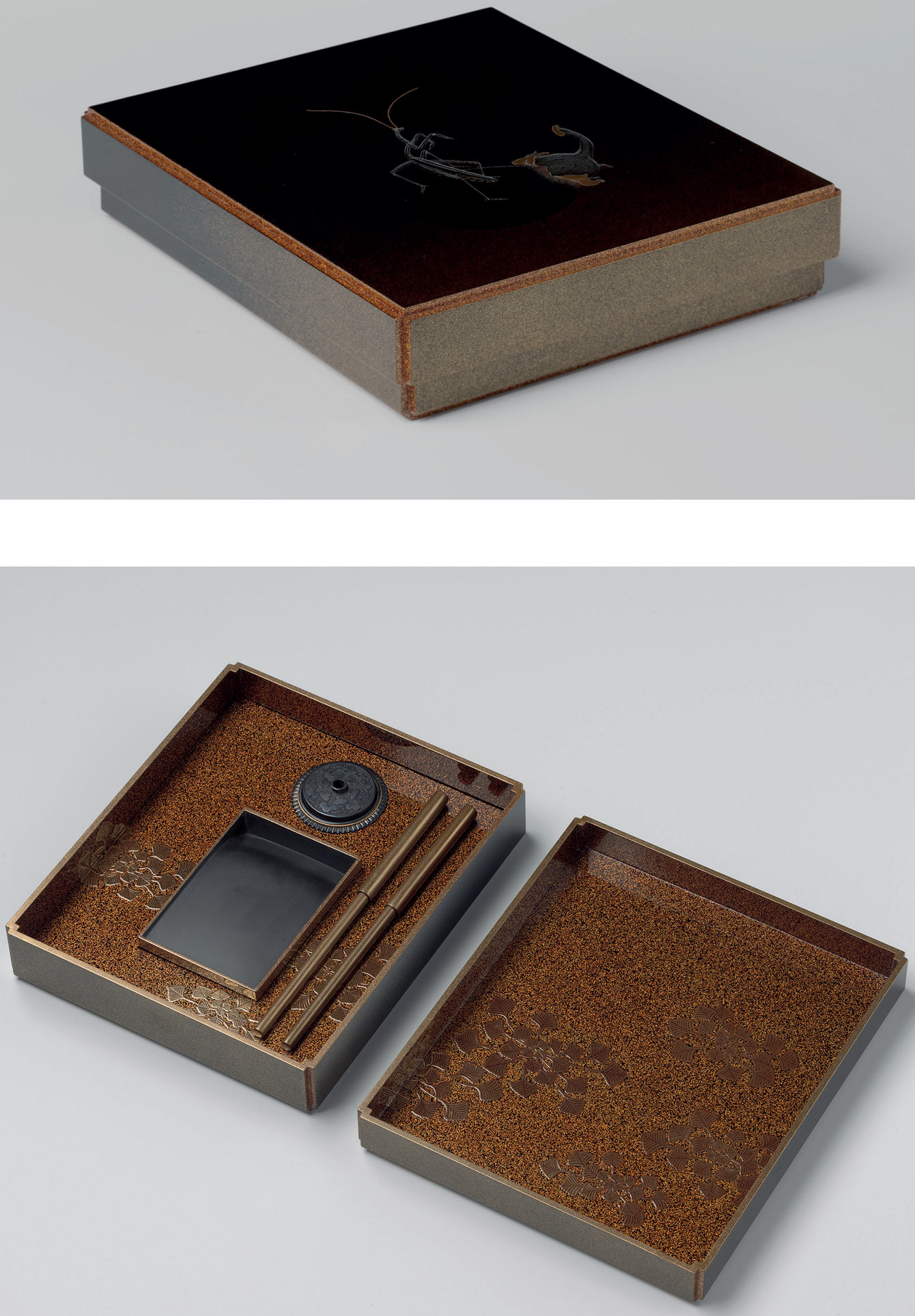
Afb. 4

Detail van nashiji

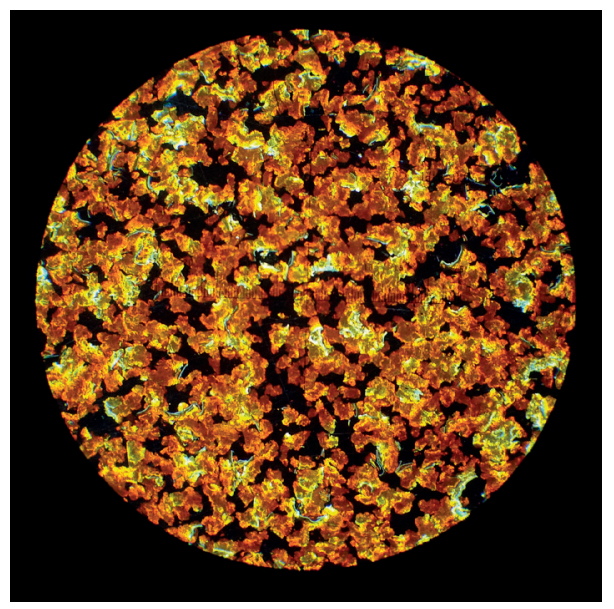

\section{Laktechnieken}

Zowel de bidsprinkhaan als de aubergine zijn grotendeels uitgevoerd in takamakie hoogreliëf met details in het vlakkere hiramakie. De bidsprinkhaan heeft een grijzige kleur (wellicht geoxideerd zilver) met details in goudlak. De licht opbollende vrucht van de aubergine heeft een spiegelend zwart oppervlak dat contrasteert met de zwarte ondergrond doordat daar in afnemende dichtheid (bokashi) fijn goudpoeder op is gesprenkeld. De steel van de aubergine is gemodelleerd in meer sculpturale hoogreliëf lak met een korrelig oppervlak (sabi, een mengsel van lak en een poeder van gebrande klei).

De uitwaaierende planten op de binnenkant zijn aangebracht in laagreliëf hiramakie goudlak. Met het goud is hier iets eigenaardigs aan de hand. De reflectie ervan heeft een zacht aspect, dat misschien nog het beste te omschrijven is als 'wasachtig'. Dit type goudlak komt voor in veel van Hōbi's objecten en kan gelden als een karakteristiek voor zijn werk. De rijke gouden ondergrond van de binnenkant is tot stand gekomen met gebruikmaking van goudsnippers. Na de drie eerder in Aziatische Kunst besproken hoofdtechnieken van makie (takamakie, hiramakie en togidashi) vormt de met goudsnippers besprenkelde ondergrond, nashiji, de vierde belangrijke techniek van het 'gesprenkelde beeld' (afb. 4). De werkwijze is als volgt: eerst worden goudsnippers met het bamboe kokertje, de tsutsu, uitgestrooid op de nog natte ondergrond, zoals chocoladevlokken op een besmeerde boterham. Na het uitharden van de lak worden de goudsnippers, die deels uitsteken boven het oppervlak, afgedekt en gefixeerd met een laagje transparante lak. Vervolgens worden enkele lagen aangebracht van een hoogwaardige transparante lak die een gele kleur heeft gekregen door vermenging met plantaardige bestanddelen, zoals gardeniapeulen. Elke laag wordt natuurlijk grondig gepolijst. Het eindresultaat is vernoemd naar het patroon op de schil van Japanse peren: nashiji of 'perenhuid'. Doordat de goudsnippers niet op gelijke diepte in de laklaag liggen en bovendien niet precies horizontaal ontstaat er een scala aan sprankelende goudtinten, die zo karakteristiek is voor deze techniek. De meeste binnenkanten van medicijndoosjes (inrō) en de meeste ongedecoreerde binnenkanten van kleine of grote dozen zijn met nashiji bedekt. 
Maar het is niet altijd alles goud wat er blinkt, want de gele kleur van de gardeniapeulen kan maskeren dat bij goedkopere uitvoeringen van nashiji de snippers niet gemaakt zijn van goud, maar van zilver of zelfs van tin. Door de eeuwen heen zijn talloze varianten van nashiji toegepast, die van elkaar verschillen naar gelang van de grootte van de metaalsnippers, de dichtheid van strooien en of de snippers gelijkmatig dan wel in wolkenpatronen zijn uitgestrooid.

\section{Basislagen en ondergrond}

De schrijfdoos Bidsprinkhaan heeft een prachtig strakke ondergrond. Om een dergelijk resultaat te bereiken is heel wat arbeid verricht. De behandeling van de houten kern en de zorgvuldige opbouw van de basislagen zijn essentieel voor de stevigheid en bovendien van groot belang om oneffenheden aan de oppervlakte te voorkomen.

Zoals op afbeelding 5 is te zien zijn er talrijke bewerkingen nodig voordat de lakmeester aan de decoratie kan beginnen. Deze voorbereidingen vallen uiteen in twee fases, die shitaji en uwanuri worden genoemd. Deze terminologie wordt in de lakkunst zelden gebezigd en komt hier uitsluitend aan de orde om te kunnen begrijpen hoe belangrijk deze onderlagen zijn voor het uiteindelijke resultaat.

Afb. 5

Schematische dwarsdoorsnede door een lakobject (aangepast naar de afbeelding op p. 33 van Christine Shimizu, Urushi: Les Laques du Japon, Flammarion, 1988)

(linnen)

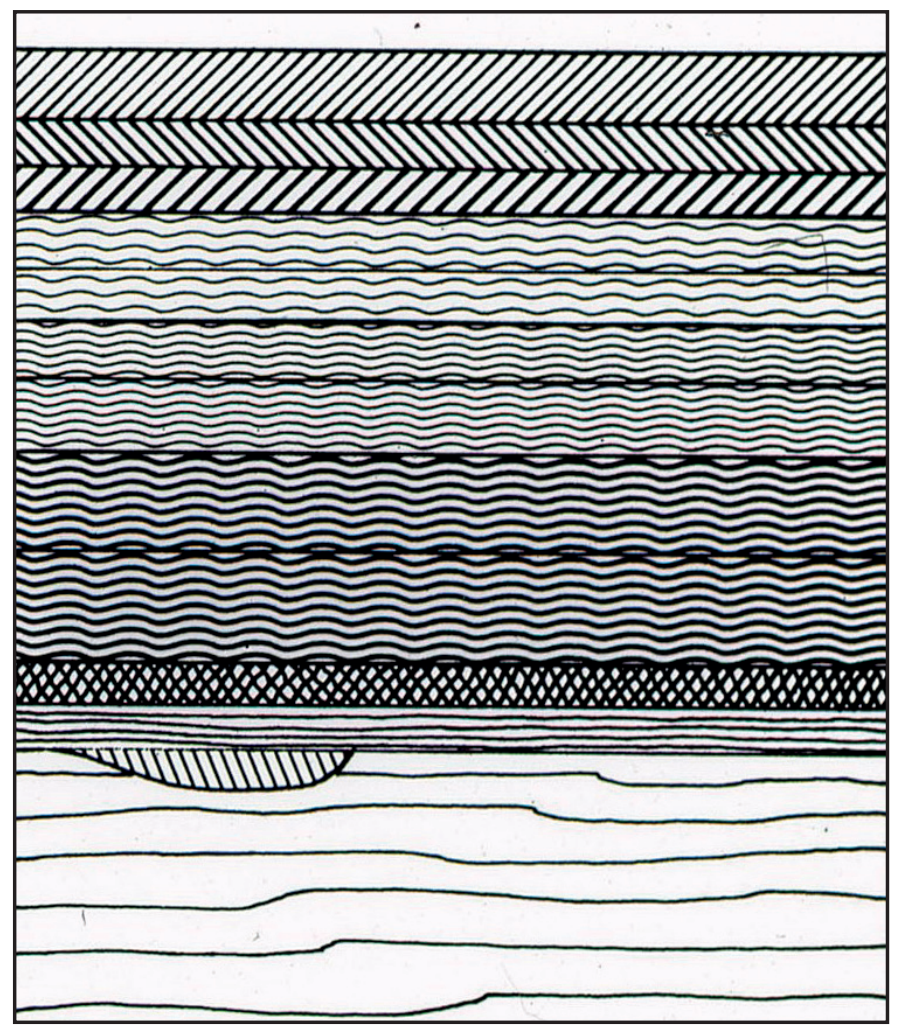


Afb. 6

Inscriptie van de titel op de buitenkant van het deksel van de tomobako (boven) en de signatuur op binnenkant ervan (onder)
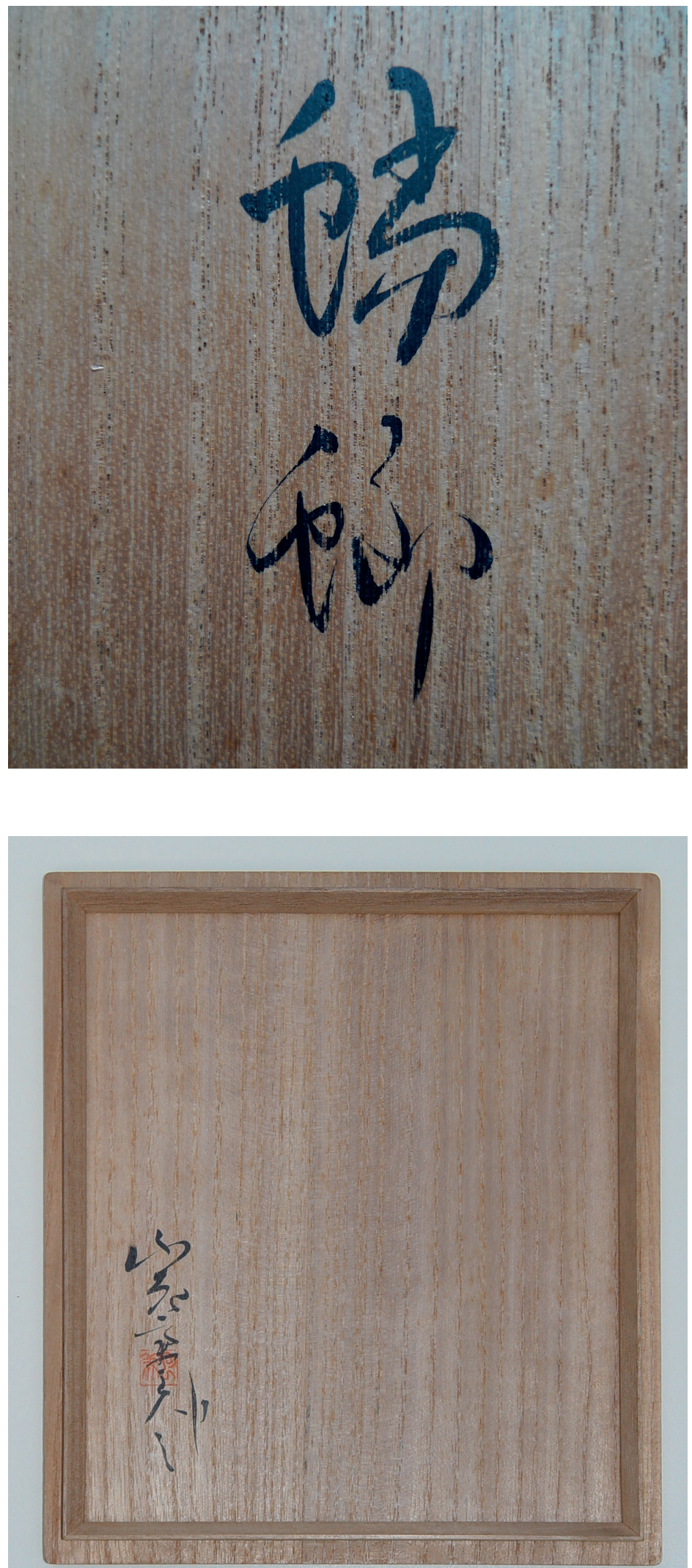


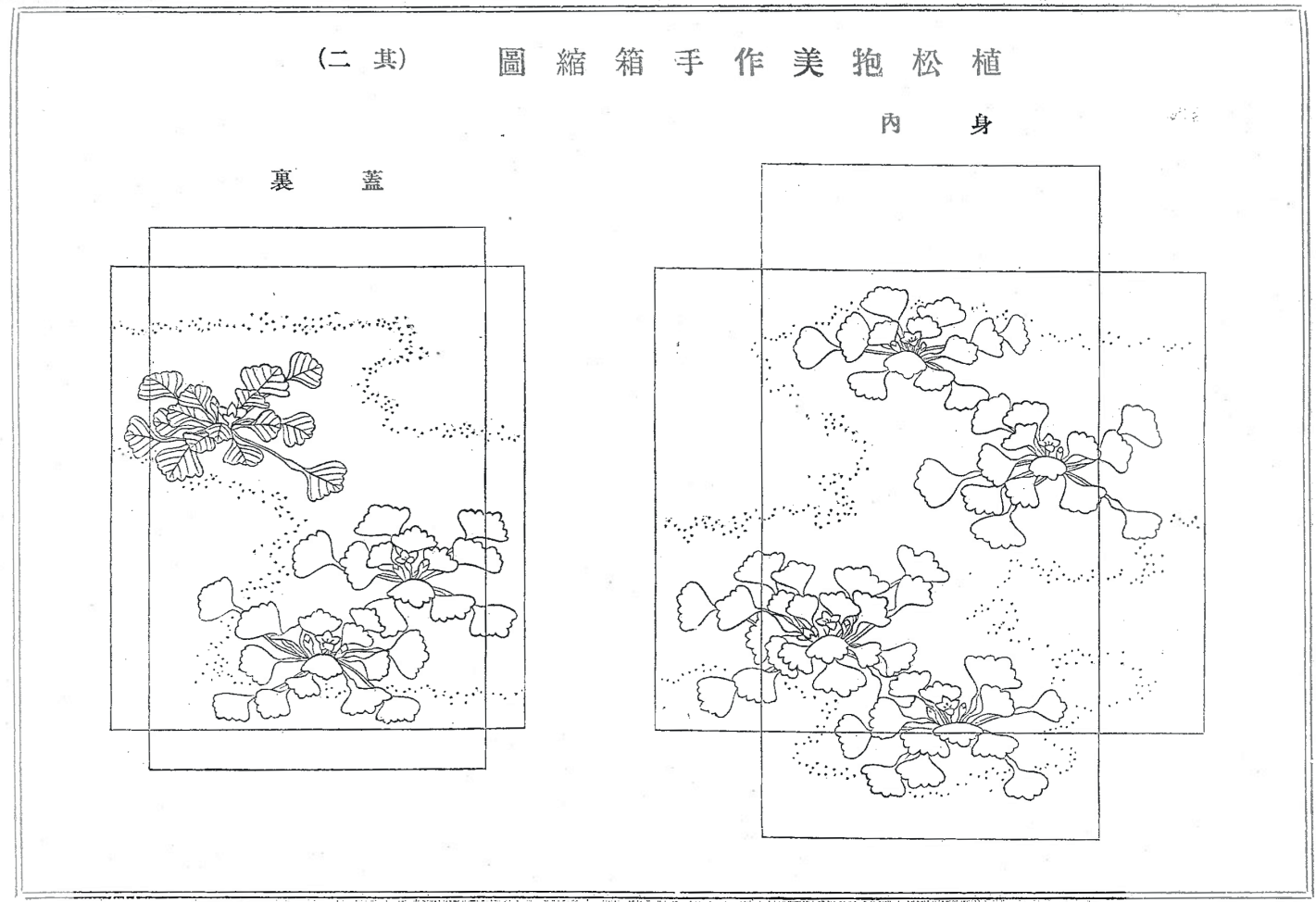

Afb. 7

Ontwerptekening van Uematsu Hōbi, gepubliceerd in jaargang 1905 van het Tijdschrift van de Japanse Lakvereniging
Bij de opbouw van de onderste basislagen of shitaji (shita betekent 'onder', ji betekent 'laag') worden eerst de oneffenheden en de poriën van het houtoppervlak met lak gedicht. Vervolgens wordt ter versteviging een laag linnen op het oppervlak geplakt met een mengsel van lak en rijstpasta. Het volgende zestal lagen bestaat uit lak vermengd met gedroogde kleipoeder of lak vermengd met steenpoeder. In deze fase is de houten spatel het gereedschap om de laklagen op te brengen en te egaliseren. Elke laag wordt uiteraard in de muro uitgehard om vervolgens geschuurd te worden met schuurpapier of slijpsteentjes.

De bovengelegen basislagen of uwanuri bestaan uit drie lagen zwarte lak, die worden opgebracht met de spatel en een breed, plat penseel. Elke laag hardt uit in de muro om daarna nat gepolijst te worden met een stukje houtskool. Pas nu kan de decoratie beginnen.

Het zal duidelijk zijn dat het schuren en polijsten tot de meest inspannende en tijdrovende werkzaamheden van de lakmeester behoren.

Zij dragen in hoge mate bij tot het eindresultaat. Zonder goede basislagen wordt het niets.

In I987 maakte Toshi Washizu de prachtige korte documentaire Bone, Flesh, Skin: The Making of Japanese Lacquer. ${ }^{1}$ Hierin worden de flinterdunne decoratielagen vergeleken met Skin de robuustere passislagend męt 01:42:48PM 
Flesh en de houten kern met Bone. Compacter kan de opbouw van een lakobject eigenlijk niet worden uitgedrukt.

\section{Tomobako en ontwerptekening}

Op de buitenkant van de houten verpakkingsdoos staat met zwarte inkt de titel Tōrō of Bidsprinkhaan geschreven en op de binnenkant de handtekening 'Furosai' met het rode zegel 'Uematsu' (afb. 6). Uematsu Hōbi gebruikte in zijn jonge jaren de kunstenaarsnaam Furosai; tot in welk jaar precies is niet duidelijk.

Indien de lakdoos niet gesigneerd is, geldt de signatuur op de tomobako om de doos tot een authentiek werk van de betreffende lakmeester te verklaren. De signatuur op de tomobako wordt weliswaar gezien als een iets zwakker bewijs dan een signatuur op de lakdoos zelf, maar wordt niet slechts als een toeschrijving beschouwd. Voorwaarde is dan dat de verpakkingsdoos (wat betreft afmetingen, vorm en patina) overtuigend past bij de lakdoos en bij de tijd waarin deze werd gemaakt.

In dit geval bestaat er nog aanvullend bewijs dat Uematsu Hōbi (Furosai) de auteur van de schrijfdoos is geweest, omdat hij in I905 een ontwerptekening heeft gepubliceerd in het Tijdschrift van de Japanse Lakvereniging (Nihon shikkōkai zasshi), waarvan de decoratie sterk overeenkomt met de binnenkant van de schrijfdoos Bidsprinkhaan (afb. 7). Het is daarom aannemelijk dat deze doos in de periode I905-I9Io is vervaardigd, nog voordat Hōbi in de ban raakte van de esthetiek uit vroeger tijden.

- In 1975 is Jan Dees geboeid geraakt door de lakkunst van Japan. Naast zijn werk als gastro-enteroloog verricht hij sinds de late jaren 80 in Europa en Japan onderzoek naar lakkunstenaars uit de periode I890-1950. Hieruit is in 2007 het proefschrift Facing Modern Times: The revival of Japanese lacquer art 1890-I950 voortgekomen.

NOOT

I De documentaire is te bekijken op YouTube https://www.youtube.com/ watch?v=NJknAootemI (I2 januari 20I6). 
VERKLARENDE WOORDENLIJST

Bokashi het bestrooien van een lakoppervlak met goudpoeder in gelijkmatig afnemende korreldichtheid

Inrō medicijndoosje, dat welgestelde mannen aan de gordel droegen

Makie 'gesprenkeld beeld', de meest karakteristieke van alle Japanse laktechnieken: 'sprenkelen' van goud- en zilverpoeder in de nog niet uitgeharde lak. Voor het begrip van makie zijn drie technieken van wezenlijk belang. [Voor uitvoerige uitleg van de technieken: zie Aziatische Kunst 44/3 (2014): II-I5]:

Takamakie - hoogreliëf

Hiramakie - laagreliëf

Togidashi - uitgeslepen of teruggeslepen decoratie

Muro een speciaal voor het uitharden bestemde kast met de benodigde klimaatcondities

Nashiji 'perenhuid'; met goudsnippers besprenkelde ondergrond. Naast takamakie, hiramakie en togidashi vormt nashiji de vierde belangrijke techniek van het 'gesprenkelde beeld'

Sabi een mengsel van lak en een poeder van gebrande klei om een korrelig oppervlak te creëren

Shakudo legering van circa 95\% koper vermengd met circa $5 \%$ goud en zilver en daarna gekookt in een zuurbad, waardoor een blauw-zwart patina ontstaat

Shitaji de onderste basislagen (shita betekent 'onder', ji betekent 'laag')

Tomobako een samentrekking van tomo (vriend) en hako (doos), houten verpakkingsdoos

Tsutsu een hol bamboe kokertje dat aan één kant is voorzien van een zijden gaasje, waarmee metaalpoeder of metaalvlokken worden uitgestrooid in de nog niet uitgeharde lak om het 'gesprenkelde beeld' te creëren

Uwanuri bovengelegen basislagen 